\title{
BIO STATEMENTS
}

Ben Fenton-Smith is a lecturer in the School of Languages and Linguistics at Griffith University in Brisbane, Australia, and was formerly Assistant Director of the English Language Institute at Kanda University of International Studies, Japan. He is currently involved in the development of, and research into, a university-wide English language proficiency strategy for Griffith University's international student body.

Michael J. Torpey was the former Director of the English Language Institute at Kanda University of International Studies in Chiba, Japan, and currently serves as an external consultant. He received his Doctorate in Education from Teachers College, Columbia University, New York. His research interests include conflict resolution, social organizational psychology, intercultural communication, education program management, curriculum renewal, professional development and second language teacher education.

\section{CONTACT DETAILS}

Ben Fenton-Smith

School of Languages and Linguistics

Griffith University

170 Kessels Rd

Nathan, QLD, 4111

Australia

Email: benfento@gmail.com

Phone: +61 737356764

Michael Torpey

English Language Institute

Kanda University of International Studies

1-4-1 Wakaba, Mihama-ku

Chiba-shi, Chiba-ken, Japan 261-0014

Email: torpey@kanda.kuis.ac.jp 


\title{
Orienting EFL Teachers: Principles Arising from an Evaluation of an Induction Program in a Japanese University
}

Ben Fenton-Smith, Griffith University, Australia

Michael John Torpey, Kanda University of International Studies, Japan

\begin{abstract}
Despite the ubiquity of EFL teachers globally and the weight of evidence about the importance of training for new expatriate staff in international settings, the process of orienting EFL instructors to new workplaces and unfamiliar cultural surroundings has yet to be researched. This article presents the results of a program evaluation of a two-week induction for 22 new English teachers at a private foreign languages university in Japan. The views of a range of stakeholders were obtained (beginning teachers, experienced teachers and management), as were perspectives at different points in time (before and after induction, one semester later, one or more years later). The evaluation resulted in a clear picture of the strengths and weaknesses of the orientation program, which in turn led to the implementation of a range of measures to improve current practice. The findings also gave rise to the proposal of a framework outlining the major areas that all EFL orientations need to consider.
\end{abstract}

\section{Keywords}

EFL, induction, orientation, program evaluation, language program management, teacher education, teacher training, professional development 


\section{Introduction}

In this paper we report on the evaluation of an orientation/induction program for expatriate EFL lecturers in the English Language Institute (ELI) of a private Japanese university. We define 'orientation' as a professional practice 'designed to facilitate the entry of new recruits to an organization and to equip them to operate effectively within it' (Trowler \& Knight, 1999, p. 178). The findings from this local formative evaluation inform the adoption of measures to improve current practice, but also contribute to the development of situated theories which 'establish a platform for the design and implementation of similar programs in related contexts' (Kiely \& Rea-Dickens, 2005, p.15).

Research on preparatory training for entry into cross-cultural settings is increasingly important in a globalized world. Two literature reviews (Littrell, Salas, Hess, Paley, \& Riedel, 2006; Wood \& El Mansour, 2010) refer to the crucial role of employee orientation in international business. Numerous studies have also been done on acculturating international students (e.g. Major, 2005; Campbell \& Li, 2008; Sawir, Marginson, Deumert, Nyland, \& Ramia, 2008), and a few papers examine the experiences of new expatriate staff in educational institutions (e.g. Lewis, 2005; Jiang et al., 2010). At the national level, particularly in the UK and USA, research has been conducted on orienting beginner primary and secondary teachers (e.g. Wong, Britton, \& Ganser, 2007; Abbott, Moran, \& Clarke, 2009; Fresko \& Nasser-Abu Alhija, 2009), and on new academic appointees in tertiary institutions in the UK, USA and Asia (Barlow \& Antoniou, 2007; Dunn \& Wallace, 2006; Trowler \& Knight, 1999, 2000).

However, on setting out to evaluate our university's EFL orientation program, we were surprised by the lack of information on this topic. Work has been done on how language 
instructors adapt to new teaching methods (e.g. the multiple studies reviewed by Van den Branden (2006) on the (re)training of teachers for task-based learning in Flanders), but our focus is on teachers adapting to new employment. A recent 276-page book on English language teaching (ELT) management (White, Hockey, van der Horst, \& Laughner, 2008) contained only two pages mentioning orientation of new staff (mostly general statements about the types of information needed, socialization, and acculturation). We found only one study within ELT: an investigation into induction practices for teachers in the ESL program at an American university (Yang, 2009).

Yang specifically worked with the primary intended users of the evaluation - the newly-hired teachers - to ascertain the extent to which the induction program met their needs and involved them in proposing changes. Like our own evaluation, the approach was utilization-focused (Patton, 2008) - i.e. program evaluation which maximizes the uses and usefulness of the process. This is in accord with a general shift in the literature away from external larger-scale quasi-experimental approaches, towards pragmatic views of evaluation as a means to inform program development via collaboration amongst multiple stakeholders (Rea-Dickens \& Germaine, 1998; Watanabe, Norris \& Gonzalez-Moret, 2009). Evaluation is viewed less as an externally mandated practice and more as a platform for internal sensemaking or inner dialogue within programs (Kiely \& Rea-Dickens, 2005; Kiely, 2009). Thus, Norris (2009) has called for more published reports explicating how evaluation actually happens. Norris, Davis, Sinicrope \& Watanabe (2009) showcase examples of program evaluation in foreign language education and it is demonstrated that the best practices: (a) prioritize local ownership; (b) view evaluation as an ongoing cycle; and (c) engender change (Davis, Sinicrope, \& Watanabe, 2009).

Yang's (2009) work, which typifies this 'local ownership', is of interest for us as: (a) it represents a first step in understanding induction in ESL contexts; and (b) it guides our 
initial foray into evaluation of induction in our own context. Understandably, Yang's evaluation does not address issues specific to EFL contexts, particularly the need to orient expatriate staff within a cross-cultural context. A major purpose of our paper is, therefore, to redress the research gap on induction practices for EFL teachers.

\section{Benefits of Teacher Orientation}

Studies on teacher orientation point to numerous benefits of the experience. Kelley (2004) has found that induction programs in US schools have proven effective in raising teacher competence and retention rates. Fresko and Nasser-Abu Alhija (2009) assert that welldesigned programs help acclimatize new teachers to a school and their classroom responsibilities, and accelerate professional growth. Drawing on studies of induction programs for beginning teachers across eight countries, Howe (2006) notes that superior programs attract and retain good candidates, improve job satisfaction, enhance professional development and improve teaching. Abbott et al. (2009) compared a cohort of beginning teachers who received an induction with those who did not, and found that the former group became more committed, resilient, and effective. In reviewing the literature on staff induction in international educational, Stirzaker (2004) summarizes the potential value of well-designed programs to: create an initial positive perception; improve both new and established members' commitment, motivation and efficiency; clarify roles and responsibilities; and contribute to the overall well-being of the organization.

As regards successful practices, Stirzaker (2004) distinguishes between inductions that are 'uninspiring information dumps' (p. 35) and those that focus on active, personalized learning. The literature suggests the most beneficial teacher inductions are typically characterized by: a positive and supportive organizational culture; a properly structured and 
paced induction; a focus on primary concerns; frequent opportunities to meet with peers and immediate managers; a clear indication that the induction is the first stage of a program of professional development; an acknowledgement of individuals' previous experiences; and an intensive mentoring component (Carver \& Feiman-Nemser, 2009; Fresko \& Nasser-Abu Alhija, 2009; Kelley, 2004; Stanulis \& Floden, 2009; Stirzaker, 2004).

A point of consensus in the literature is that the best orientation 'is a process, not an event' (Stirzaker, 2004, p.31). Although we agree with this notion, in this paper we are mostly concerned with the initial training event as part of the broader orientation process. We aim to contribute to the study of teacher induction programs by evaluating the effectiveness of this first step towards workplace adjustment and professional development.

\section{Setting, Participants and Evaluation Uses}

The university's ELI comprises over 60 language instructors (teachers and learning advisors) from various countries who design and deliver English proficiency courses to Japanese undergraduates in three departments. Their task is to improve students' communicative ability and international awareness. Most hold master's degrees in TESOL or applied linguistics and are hired on two-year contracts that can be renewed once.

Several factors particular to this setting provided the impetus for the authors of this paper - senior managers in the ELI - to undertake an evaluation of the current orientation practices; namely: the dramatic expansion of the institute (from 4 lecturers in 1989 to its current 63); the diverse mix of lecturers (from different countries, ethnicities, educational backgrounds, and teaching experiences); and the cyclical turnover due to fixed-term contracts (an average of 16 recruits per year from 2005-2010). These circumstances led to an internally-driven formative evaluation undertaken primarily to understand how effective the induction was in 
helping the recruits adjust to their new working and living environments and what areas of improvement were needed. In essence the evaluation, which sought to bring about actual benefits for the intended users of the program, was designed to answer three fundamental questions:

1. What perceptions did the various stakeholders have of the orientation program?

2. What were the strengths and weaknesses of the current program?

3. In what ways could the orientation be improved?

The main participants of the evaluation were the 22 new instructors who experienced the 2009 orientation two weeks before the official start of the school year. A second group consisted of 14 other lecturers who had already been working at the ELI for one to three years. All participants had previous teaching experience and many had taught in Japan and/or overseas, but almost all were new expatriates when recruited (i.e. not local teachers or long-term residents of Japan). A third participant group were the four managers of the ELI (including the authors of this paper), all of whom were non-Japanese with several years experience living in Japan. They each held a $\mathrm{PhD}$ and were on continuing employment contracts.

\section{Methodology}

In line with a call for program evaluation to be recast as a 'socially-situated cycle of enquiry, dialogue, and action' (Kiely, 2009, p. 99), a primarily exploratory and qualitative approach was adopted. Such an approach was believed to facilitate a richer, more complete understanding of our program as articulated by those in situ.

The evaluation therefore draws on multiple data sources (surveys, written reports, interviews, focus groups) from various stakeholders (new teachers, established teachers, 
management) at different time frames (pre and post-orientation, several months later, one or more years later). The following table summarizes the data collection procedures.

\section{[INSERT TABLE 1 HERE]}

All qualitative data was analysed using the coding software NVivo 8, which allows the researchers to identify common themes and produce 'text coverage' statistics showing the extent to which a certain theme features in a given text or texts. We refer to these percentages in reporting the findings and elaborate on their significance within the narrative text. (Percentages do not necessarily total $100 \%$ as one piece of text can be coded for multiple themes.) The coding framework established at the first stage of analysis (management data) was then used to analyse all subsequent qualitative data.

\section{Management Self-report/Interviews}

Any inquiry into the effectiveness of a program begins with an understanding of the purposes of that program. In accord, the four managers responsible for the orientation were asked the following open-ended questions:

- What are the intended outcomes of the pre-semester orientation?

- How satisfied are you with current practices?

As the management team had conducted a similarly structured orientation each year for several years, 'current practices' referred to their experiences over recent years, not just the 2009 orientation. The authors of this paper wrote their responses and emailed them to each other. They then each interviewed the other two managers who had received these questions 
beforehand. The interviews were on topic though unstructured; ranged from thirty minutes to one hour; and were audio-recorded and transcribed.

A limitation is the inclusion of the authors' own self-report data. However, we felt it would be wrong to exclude the perspective of managers from evaluations of their own programs, since this would deter those who need it most from engaging in critical selfreflection. Admittedly, such evaluations could be conducted by outside parties, but this would curtail the likelihood that such evaluations are ever carried out. As Kiely puts it, 'the task of improving a programme requires an openness about shortcomings' (2009, p. 100) - managers need to be encouraged (not discouraged) to engage in this task.

\section{Pre-Orientation Survey (New Lecturers)}

On the morning of the first day of orientation, 21 of the 22 new recruits were asked to complete an anonymous online survey (one recruit piloted an earlier version). This survey sought to investigate the recruits' perceptions and needs prior to any formal orientation.

\section{Immediate Post-Orientation Survey (New Lecturers)}

The orientation was completed on a Friday. Participants then had one weekend and two week days to prepare for the commencement of classes on the following Wednesday. Although gaining the immediate reactions of new staff to the orientation before their recollections dimmed was essential, it was decided that this was an inopportune time to administer a detailed questionnaire. They were therefore offered a non-mandatory, anonymous 
questionnaire containing only a single prompt, which was emailed 4 days after completion of the orientation:

What are your views on the orientation for incoming ELI lecturers? We are interested in feedback of any kind, both positive and negative. E.g.: What was useful, what was not? Was there anything missing? Were you particularly satisfied/dissatisfied by any aspects of it? Do you have any advice to improve it for next time?

Despite their busy schedules, 16 of the 22 responded.

\section{End of Semester Focus Groups/Survey (New Lecturers)}

Near the end of the first semester, two focus group discussions were held with new lecturers (four per group), lasting one hour each. A week prior, group members were given two guiding prompts and a copy of the orientation schedule. It was not possible to hold focus groups with all first-year lecturers, so non-participants were sent the same questions below via an online survey (two responded):

1. Please take a look at the orientation schedule for March 2009. This is the schedule that you undertook when you first arrived here. What recollections - good or bad - do you have of this orientation period? That is, we'd like you to try to remember how you felt about the various aspects of the orientation at the time.

2. Now that you are a more experienced member of the ELI, what do you think about your initial impressions of the orientation? If you had to design an orientation for incoming ELIers, what would you change about the one that you undertook? Why? What aspects of it would you not change? Why? 
As the researchers were also ELI managers, an independent moderator was selected to ensure open critique of orientation practices. To protect the identity of participants no audio or video recordings were conducted. A former ELI lecturer moderated the sessions, taking notes that were later submitted to the researchers as summarizing narratives interspersed with unattributed reported speech.

5 End of Semester Focus Groups/Survey (Experienced ELI Lecturers)

As orientations in preceding years had followed the same structure, it was decided to seek the views of experienced ELI lecturers too. This would allow comparison of the perceptions of newcomers with those of veterans: i.e. determine which of the newcomers' judgements were supported by the experienced group, which were different and which had dissipated or changed over time.

The process outlined in section IV.4 (above) was thus replicated for experienced lecturers. Two focus group discussions were held in which second-year lecturers (four per group) discussed views on their own orientation, using prompts as in IV.4. Prompts were also sent to all other experienced lecturers (second, third and fourth-year) via online survey (six responded).

\section{Findings}

1 Management Self-report/Interviews 
Although the four managers emphasized different aspects of the orientation, there were no major points of disagreement. All of the 'intended outcomes' and 'current practices' they referred to could be classified within four broad domains. These are depicted in Figure 1, with percentages showing the amount of text that each domain took up in the management responses. ('Q.1' refers to intended outcomes; 'Q.2' refers to satisfaction with current practices.)

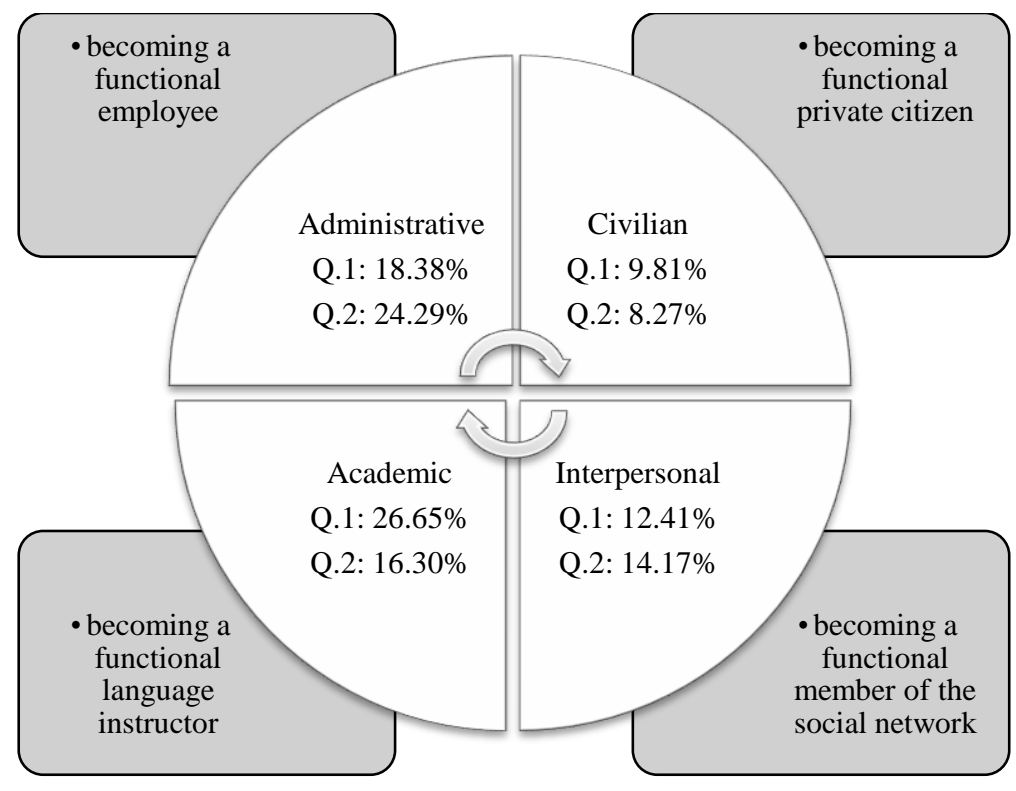

Figure 1 Management perspectives on orientation issues

Each domain could be further subdivided, as the following sections detail.

a Administrative Domain

\section{[INSERT TABLE 2 HERE]}

The term 'administrative' was used to encompass the non-academic processes and procedures that are required to function as an employee of the institution. Management identified several 
intended outcomes in this domain: concluding and clarifying contract terms (e.g. working hours), absorbing background information about the institution, understanding behavioural expectations (e.g. dress code, grievance procedure), receiving a loan (e.g. for housing), and organizing work space (e.g. office, computer log-in). The findings indicated two areas of concern:

- contract: having newcomers arrive up to two weeks before their contract officially commenced was a source of contention;

- work space: the occasional tardy provision of work needs (e.g. offices, computers, keys) made newcomers feel unsettled and unable to commence lesson preparation; additionally, this might have cast management in an unprofessional light.

\section{b Civilian Domain}

\section{[INSERT TABLE 3 HERE]}

The term 'civilian' refers to life outside work: how new recruits become functioning private citizens. For intended outcomes, two managers mentioned the need for education about lecturers' status within the culture, two mentioned practical setting-up issues, such as banks and utilities, and two mentioned helping newcomers find housing. Table 3 shows that the major issue was finding places to live, specifically:

- in the past some new recruits were unable to settle into an apartment before term started;

- and information about setting up life in Japan was not entirely made available ahead of time (e.g. online). 
c Academic Domain

\section{[INSERT TABLE 4 HERE]}

The term 'academic' refers to employees' roles as educators. As Table 4 shows, the most pressing intended outcome was providing information about courses: what recruits will be teaching, as well as how and who with. Other outcomes concerned research expectations, understanding the students, gaining knowledge of the institution's pedagogical approach, and learning about opportunities for career advancement. Shortcomings centred on courses:

- information about teaching schedules not being made available until the second-half of the orientation;

- practical constraints on sending out teaching schedules earlier (e.g. late withdrawals requiring schedule reshuffles);

- inconsistency in the quality of orientation to the various departmental subjects;

- teaching materials not being made available early enough;

- difficulty in familiarizing new staff to complex technological equipment and online course management systems.

d Interpersonal Domain

[INSERT TABLE 5 HERE] 
The term 'interpersonal' captures the role of the orientation in facilitating staff relationships. All four managers mentioned two intended outcomes: to have recruits feel secure within their team and to have them bond with other staff. In assessing current practices, social gatherings and informal meetings contributed to these aims. However, there was one concern:

- the emotional stability of individuals was somewhat undermined by not having all aspects of their personal space arranged (e.g. an office, a computer, internet access)

e Other

An issue related to all four domains was information delivery and the ordering of sessions. $31.40 \%$ of management's feedback on current practices concerned this topic. Specifically:

- too many lecture-style sessions become tiresome as 'information overload' takes effect;

- group size affects the willingness of some participants to speak up, while the management/newcomer power imbalance may inhibit others.

Finally, tasks required of newcomers that are unrelated to orientation may be viewed as distracting (e.g. in previous years some newcomers reported experiencing stress when asked to invigilate a campus-wide proficiency test).

\section{Pre-Orientation Survey}

Results of the survey conducted with new teachers immediately prior to the orientation are presented in both percentage and aggregate terms, with the most chosen result for each item highlighted. 
Table 6 presents responses to the prompt, 'Please rate your level of knowledge about each of the following.' The purpose of the question was to understand what newcomers did and did not know before commencing the orientation.

\section{[INSERT TABLE 6 HERE]}

There were few areas that lecturers rated highly. They appeared to have a good knowledge of Japanese culture, its education system, and practical life matters, but less about specifics such as housing and students. Their understanding of the contract was strong, but their understanding of job specifics (courses, research, colleagues, professional development, technology) was weak. Of particular note is the fact no one had a high level of knowledge about courses or course management systems.

Table 7 presents answers to the question, 'How much knowledge about the ELI have you gained from the following sources?' This question was inserted so that management could make decisions about the strengths and weaknesses of knowledge transfer prior to arrival.

[INSERT TABLE 7 HERE]

The job interview emerged as the primary source of newcomers' knowledge. Websites representing the institution were rated poorly, but a custom-made website for incoming teachers rated quite well. Communications from management were reasonably informative, while less than half of new lecturers could garner some information from existing or former teachers. 


\section{Immediate Post-Orientation Survey}

When asked to give feedback on the orientation four days after completion, $88 \%$ provided positive overall assessments, with no participants providing a negative overall assessment. They appraised it in terms of usefulness (e.g. 'it was very helpful'), enjoyment (e.g. 'I had a good time'), organization (e.g. 'very well run', 'thorough') and comfort (e.g. 'stress-free', 'comfortable').

An overriding issue, mentioned by $63 \%$ of respondents, was the relationship between the amount of information/activities and the time available. Although $60 \%$ of those who commented said there was a lot to learn and do (e.g. 'the only drawback was the sheer amount of information relative to the amount of time'), $80 \%$ thought that the time was well organized (e.g. 'I enjoyed the pacing of the orientation as it didn't overwhelm us'). This apparent contradiction is explained by the fact that many respondents appreciated that a hectic schedule was a necessary evil (e.g. 'The orientation was as smooth as an orientation can be considering the amount of information being relayed.') Against this, $30 \%$ of those who mentioned the timing issue thought the information/activities would benefit from a different schedule, noting, for example, that 'it seemed to be stretched out with really short days'.

Nearly half of respondents (44\%) offered specific suggestions to alter the manner in which information is made available or to encourage the continuation of a current practice. Ideas included sending 'an information packet (either digital or analog) to incoming teachers ... before arriving as optional reading', setting up an 'FAQ site on moving/practical matters' to avoid newcomers making 'the same mistakes', and providing 'access to the materials before orientation begins'. There were comments on the provision of refreshments ('coffee 
and tea ... helped to keep a relaxed atmosphere'), the location of the meeting room (it 'helped us to feel part of the ELI'), use of visually stimulating PowerPoint slides, and a session in which newcomers were grouped with experienced staff (it 'allowed the new members to ask questions and by giving the senior members the opportunity to give advice and share their thoughts, gave a nod of acknowledgment to their prior experience here').

Of the four major domains - administrative, civilian, academic and interpersonal - the administrative and interpersonal were the least contentious. (However, since teachers were only asked to respond to a single, catch-all prompt, these findings are tentative - teachers may have commented on other aspects of the orientation if they had been specifically asked.) Administrative matters received six comments, from $38 \%$ of respondents, including three suggestions that a 'more complete campus tour and a map' be provided. The interpersonal component received 5 comments from $31 \%$ of respondents, all complimentary (e.g. 'it was a great way to get to know new colleagues', and it 'allowed us to get to know each other better and build a nice sense of community').

Comments on the civilian and academic domains were made by more people, more often and at greater length. Civilian issues were raised by $50 \%$ of new staff, in ten comments. Six people expressed frustration about the process for finding accommodation (e.g. 'it would have been useful to have a short orientation on what to expect with housing'), although two others praised the process. Setting up bank accounts and utilities also seemed to be frustrating, described by four people in terms such as 'chaotic and cumbersome' and 'tough'. In general, participants felt they were taken 'by surprise in terms of the time required' and had not 'been properly informed' and as a result 'I have had to be the one to seek out most of the information'.

The lengthiest comments were reserved for the academic domain. $44 \%$ of respondents mentioned this aspect, across eight comments. The main issue (6 comments) was that course 
information was insufficient, especially in comparison to other aspects of the orientation. Participants wanted 'more focus on the classes we are teaching', 'more time dedicated to discussion of the courses', 'more advice on class syllabus and what we are expected to teach', 'longer meetings for subjects' and 'examples of lessons'. There were also two comments critical of the timing of academic information, stating that 'by the time we started those [subject] orientations, I felt so brain dead from the administrative orientations and apartment searching, that I really couldn't take it all in'. As a result, 'I've done a lot of catch up on weekends trying to get my head around what I'm teaching' and 'as I sit now, trying to write up course outlines and lesson plans I have a lot more questions than I thought'.

\section{End of Semester Focus Groups/Survey (First Year Lecturers)}

New recruits were asked to reflect again at the end of the semester, either as a participant in a focus group or via an online survey. Table 8 shows the percentage of text devoted to various aspects of the orientation, after the focus group transcriptions and survey responses were coded for common themes.

\section{[INSERT TABLE 8 HERE]}

The academic domain received the most comments (42.15\%), particularly the issue of courses $(39.02 \%)$, partly because participants were asked to review the orientation schedule, which contained several sessions on academic matters. Three curriculum issues were commonly raised: assessment (15.41\%), content (13.67\%), and how courses were to be taught, particularly technology (11.40\%). Assessment was an issue for several recruits who 
felt uninformed about the meaning of grades: 'Some kind of norming is needed, some kind of standardization'. The multicultural workplace setting clouded the issue further, with comments on the differences between teachers ('the UK and American version of grades are important') and between teachers and students ('if some teachers aren't popular because of the grades they give, then that's not fair on the teacher'). Regarding content, several people drew attention to the lack of time devoted to this ('One hour just isn't enough at all') as well as the timing ('maybe half a planning day earlier on [would be better], so that we have a chance to get the information and actually process it'), and requested concrete ideas ('even a short demo lesson from an older teacher'). However, views were not uniform, as one person praised the brevity, saying that the course orientations 'were quite good - short and sweet' and claiming that more information 'would just have gone in one ear and out the other'. Time spent on instructional technology (course management systems, classroom computers, and listening and video equipment) was clearly problematic: 'we did the activity with the BLS [blended learning space] and then I forgot about it and then I went into a BLS myself, I had to learn it all over again, so for me it wasn't that useful'. Several pointed out that curricular knowledge has to precede technological instruction: 'training like that is much more valuable when you know what you are actually teaching'.

The major issue within the civilian domain was finding an apartment (13.24\%). Participants felt frustrated by the scheduling of apartment hunting and work-related orientation sessions on the same days. For those without a place to live, it was difficult to concentrate on anything else: 'My mind at the start was very much on finding a place to live and I know it was the same for the others too. It's difficult to focus on other things when that is so important.' They thought there was insufficient time ('people were finding it tough to rush around in the small windows and would probably have preferred to have whole days to look for a place') and inadequate support ('it was very obvious that he [the estate agent] was 
trying to offload all his terrible places on us'). For those that did have a place to live, there was a sense of time wasted: 'I understand if you are coming from abroad but don't make other people come here that don't need a house'.

Lecturers also expressed dissatisfaction with the administrative side of the orientation. Work space issues were raised four times $(4.36 \%)$ and contract issues three times $(2.95 \%)$. Regarding work space, lecturers were inconvenienced without offices to enter immediately, keys to lock doors, or laptops to work on. Some felt they 'couldn't do anything with their spare time' and were unable to start work ('we need to feel that we are being productive'). They also expressed a desire for a more efficient way to assign people to share offices. (Other issues were only mentioned once.) Regarding the contract, lecturers noted it did not specify that orientation began a week before the first paid workday.

The interpersonal domain received few comments (5\%), although a session in which new recruits quizzed established teachers was highly valued, leading to the suggestion of more formal mentoring.

Finally, many opinions of a general nature ('Overall comments' - 19.28\%) were given, particularly about the overall structure of the program (16.37\%). Almost all of these were objections to down time in the schedule: e.g. 'I don't mind starting if there is lots to do, but I don't like having my time wasted at all'. Another major objection was to involvement in the invigilation of the university language proficiency test (7.91\%), which was unrelated to the orientation.

5 End of Semester Focus Groups/Survey (Experienced ELI Lecturers) 
Experienced lecturers were asked to recall their own orientations, either as a participant in a focus group or via an online survey. Table 9 shows the extent to which various topics were raised, again expressed as text coverage percentages.

\section{[INSERT TABLE 9 HERE]}

General assessments of the orientation ('Overall comments' - 13.21\%) show that lecturers shared a feeling of 'information overload' but also recalled being 'just happy that there was an orientation at all'. However, two lecturers felt the institution oversold the message of 'how good it is'. There was a relatively high percentage $(14.86 \%)$ of comments about discomfort at being asked to administer the proficiency test.

Feedback on administrative aspects (14.06\%) mainly concerned the contract (8.89\%), specifically the fact that the orientation started before the first paid day. There were also comments about work space (the lack of an office, computer and password) and the need for background information - particularly about the university's departmental structure. Regarding civilian matters $(10.16 \%)$, there were two references to the frustrations of apartment hunting. The few comments $(3.42 \%)$ on interpersonal matters were positive.

The dominant theme of the feedback was academic concerns $(57.55 \%)$, particularly how the orientation prepared new staff to actually teach ('Courses' $-30.24 \%$ ). It was felt that there 'was not enough information provided about classes' and that such information should come 'sooner rather than later' (perhaps 'by email' or 'give us something to read on the aeroplane'). Additionally, there were criticisms that CALL (computer-assisted language learning) instruction was haphazard ('too many people, no internet connection, wrong passwords, nobody could follow'); that assessment practices were unclear ('What does an "A" mean?'); and that it was difficult to connect with colleagues who teach the same 
subjects. Self-access learning was also raised (14.09\%), with some complaining that a session about the SALC (self-access learning centre) was activity-based rather than directly informational and 'doesn't have much relevance for teachers'. Some felt the SALC-related notion of 'autonomous learning' (and the ELI's pedagogical philosophy more generally) was inadequately explained. Finally, the issue of students was raised $(12.57 \%)$ - five lecturers commented that management gave an overly positive impression of both student motivation and proficiency levels.

\section{Discussion}

The first major finding of this paper emerges in the analysis of the management data and is supported in the qualitative feedback from other ELI lecturers. This is the framework of four meta-functions (academic, civilian, administrative, interpersonal) for inductions in EFL institutions, each corresponding to a role deemed essential for successful transition into the workplace: teacher, private citizen, employee, and member of the social network. The framework did not precede this inquiry and therefore did not influence the design of previous orientations. Instead, the framework emerged from this evaluation and can provide a rationale for the design and delivery of EFL orientations in other settings. Combined with the further sub-categorization of elements in Tables 2-5, it constitutes a useful set of guidelines for managers, just as Yang's (2009) ESL evaluation resulted in 'checklists for pre-semester teacher induction, to be used by ELI administrators' (p. 94).

The remainder of this section provides a synthesis of all results for each of the four domains, focussing on themes that consistently arose and points of contention.

\section{Academic}


Academic matters - particularly courses - received the most attention in every data set. The findings indicate that a bedrock principle for those planning orientation programs is to provide course information in a timely manner. Staff need to process the information (look at outlines, materials etc.), discuss it (connect with experienced staff who have taught the same courses), and act on it (prepare initial lessons), perhaps even before arrival. The longer that new staff go without clarity about upcoming teaching assignments, the less comfortable and engaged they are with other orientation matters. However, EFL managers may have difficulty providing course information pre-arrival for two reasons: (a) if a teacher withdraws at the last minute (the possibility of which is high in international employment), course designations may have to be re-assigned; and (b) incoming recruits may have limited time to digest information before arriving (when asked, only $14 \%$ of new recruits reported having 'a lot of free time' prior to arrival).

Second, differing expectations about what constitutes 'materials' may arise among the teachers: some expect clear user guidelines while others view this as the teacher's job to work out. Institutions that promote certain pedagogical principles (e.g. in the ELI, classes are expected to be communicative and task-based with a focus on learner autonomy) have a greater need for the inclusion of teaching and learning theory in their orientation; however, the time required for explicating and assimilating theory (with varying perceptions about its immediate necessity) creates further challenges for orientation planning. An example was the SALC orientation which aimed to replicate self-access learning by having teachers brainstorm and explore the SALC for themselves. While some lecturers appreciated this session, others were dismissive. This shows the difficulty of covering theoretical issues which may be perceived as not of immediate concern. 
Assessment was an area neglected by management, none of whom referred to it in their orientation overviews. Although assessment was not initially mentioned by new recruits (see section V.3), by the end of semester, when grades were due, it had become an issue (section V.4), and was also a problem mentioned by experienced teachers (section V.5). Managers need to be aware that assessment practices vary among countries and therefore norming is particularly necessary in EFL environments.

In addition, the data indicated some mismatched perceptions about students. For example, one manager's view that 'we're very lucky' to have 'good students, very motivated students' contrasted with a teacher's opinion that 'we all got a bit demotivated when we realized our students weren't as good as they were made out to be'. EFL managers (particularly those who have worked extensively in one context) cannot assume that incoming teachers (possibly with experience in very different countries) have the same frame of reference for judging students.

Finally, technology was a major issue. A problem for EFL orientations is that teachers arrive with varying levels of proficiency (see Table 6). Tech-heavy instructional sessions can be complex and fall prey to technical glitches. The result is that teachers report having little time or mental energy to assimilate skills and are therefore reluctant to implement the technology in class.

\section{Civilian}

Securing a place to live was the second major issue (after course information) at the forefront of new teachers' minds (Table 8) and was underrated by management as an intended outcome (Table 3) - perhaps indicating there is a lack of mutual understanding concerning the extent to which the employer is responsible for taking care of the employee's civilian life. Even if 
initial hotel accommodation is supplied, it is clearly unsettling not to have a home base. The issue may have been exacerbated by the new teachers' inability to take control: in addition to language and cultural barriers, only a third of the recruits reported an adequate knowledge of Japanese housing (Table 6).

The time required to secure and furnish accommodation, set up bank accounts, utilities and so on was generally underestimated by new staff and not made clear by management. Problems ensue if a teacher is still dealing with these issues after the other parts of the orientation begin. In this evaluation, some teachers were distracted by a combination of civilian, academic and other concerns, which made it difficult to concentrate. Conversely, those who had settled into civilian life became frustrated at the orientation being put on hold while others searched for apartments.

\section{Administrative}

Several administrative matters pointed out by management as significant received no comment by staff: dress code, grievance procedure, formal contract signing, staff evaluation system, and protocol for relationships with students. It is possible that these issues were not raised as they were sufficiently addressed in the job interview and a staff handbook.

Two issues that did recur across the data sets were job contract and work space. The former is possibly not a concern for all orientations but only those, as in this evaluation, that require a commitment of time prior to the first paid day. This is reasonably common since many institutions offer contracts that begin the same month that the teaching term does, leaving it up to managers to implement an orientation as best as they can.

Work space issues may be minor but nonetheless distract from more important orientation tasks. New staff expect and need basic things when they arrive for work: 
computers, passwords, offices, and keys. These are not matters to begin addressing after they arrive, as this evaluation demonstrates. However in the ELI's case, where staff share offices, pre-assigning all 22 new teachers from around the world to communal workspaces could have led to unnecessary conflicts if incompatible individuals had been assigned together.

\section{Interpersonal}

This domain is significant for international staff orientations as it is unlikely that new recruits know any incumbents or have support networks nearby. The interpersonal component received few complaints and much praise by newcomers, incumbents and managers alike. However management made mention of it (see Table 5) roughly twice as much as teachers did (Tables 8 and 9) - perhaps because managers feel obligated to facilitate good relationships. Nevertheless the general positivity suggests that successful interpersonal outcomes can be achieved more easily than outcomes in other domains, possibly because (a) there are few of the practical complexities that beset the other areas; (b) new staff are predisposed to making friends in their new situation; and (c) experienced staff empathize with newcomers. Orientation planners should still take the initiative to ensure there is space and time for staff to meet together informally.

Several points for improvement also emerged. First, more thought could be given to facilitating interpersonal connections before arrival. As Table 6 shows, $62 \%$ of incomers had a 'low' or 'non-existent' knowledge of senior colleagues before the orientation. Their major source of information was an interactive (but rudimentary) online forum created by one of the managers (Table 7). This result suggests that opportunities for enhanced interaction via online social networking could be explored. Second, most of management's effort went into facilitating relationships among the first-year recruits, yet feedback suggested the recruits 
highly valued opportunities to bond with established staff too. Finally, the success of the interpersonal can overshadow neglect of the intrapersonal. One manager who had experienced induction a year earlier pointed out that 'we have all these group things, which is great' but 'you need thinking space too'. Recruits possibly need the time and means to be alone (e.g. an office to retreat to) and the resources to reconnect with family and friends (e.g. using Skype in privacy).

\section{Miscellaneous}

Two further items of general interest are noteworthy. First, having new staff carry out tasks not related to the orientation was poorly received. Mandatory administration of the largescale proficiency test was criticized, even by the experienced staff. Recruits typically felt unprepared and even intimidated by such demanding work so soon after arrival.

Second, although some literature on staff inductions calls for experiential, activitybased orientations (see, for example, El-Shamy, 2003), the negative appraisals that the activity-based SALC orientation received from some experienced lecturers suggest that such activities may be perceived as time wasting or patronizing by some, and are a reminder that there will be a range of learning styles present in any group.

\section{Conclusion}

We conclude by outlining the changes that were implemented in the program as a result of the evaluation, and then offer twelve principles for EFL orientations generally.

\section{Local Innovations}


The following changes were made to overall structure:

- background information is provided pre-arrival via a teachers' homepage which includes an interactive, introductory forum;

- expectations about what will or will not be provided are clarified ahead of time to minimize concerns;

- certain days are dedicated solely for practical/personal matters and other days focus only on administrative/academic procedures, with more days allotted toward the end for class preparation;

- demands with regard to administering and marking a university-wide English proficiency test have been minimized.

The following domain-specific changes were also implemented:

Academic

- sessions about academic/departmental courses are held earlier and for a longer duration;

- divergent assumptions about the nature/meaning of grades/assessment are openly discussed and guidelines are provided;

- instructional workshop on CALL/online systems is held after teachers have had subject orientations to facilitate synergy with the curriculum;

- teachers are given a better sense of their prospective students through: (a) explicit discussion of the range of ability levels; (b) examples of student work; and (c) a peerled professional development workshop focusing on Japanese university students. 
Administrative

- rationale for asking new teachers to arrive before contracts officially start is explained;

- nature of Japanese contracts (as general, somewhat flexible statements that assume a certain degree of trust between employer and employee) is clearly explained;

- provision of work spaces (offices, computers, internet) is streamlined.

Civilian

- recruits who require housing and/or are unfamiliar with Japan are encouraged to arrive earlier.

Interpersonal

- mentor program has been created, pairing current staff with new recruits.

In addition, the following actions are planned:

Academic

- explaining that the orientation involves a range of activities catering to various learning styles, thereby pre-empting possible adverse reactions of some individuals to certain types of activities as well as showcasing a pedagogical philosophy of the ELI, the notion of learner differences;

- creating sample video recordings of classroom lessons, accompanied by corresponding lesson plans and materials; 
- developing a bank of lessons/materials for use in the first few lessons of the school year;

- scheduling meetings in which current university students talk to the new recruits about the university, their classes, their challenges and expectations.

\section{Interpersonal}

- providing contexts in which new staff are not self-conscious about appearing ignorant in front of colleagues (e.g. utilizing small group/pair work and having incumbent teachers rather than management run sessions).

Several of these innovations accord with Yang's (2009) evaluation of the US university ESL teachers' orientation: i.e., the earlier arrival of some teachers, better provision of information, increased meeting time to discuss curriculum matters, and more input from veteran teachers.

\section{Twelve Principles of EFL Orientations}

The following key messages, of import to EFL inductions generally, also emerged:

1. Allay expectations about what the orientation is, how it runs and what it (and participants) can achieve.

2. Attend to four key aspects of a participant's life: academic, administrative, civilian and interpersonal.

3. Have essential civilian matters (primarily, a place to live) settled before other parts of the orientation begin. 
4. Prioritize academic matters at the start (and provide information before arrival, where practicable).

5. Focus on the most important academic matters for participants: course content, assessment, students, and facilities (especially technology).

6. Allay concerns about first classes - e.g. by scheduling preparation days and providing readymade lesson plans/materials.

7. Resolve work space issues prior to arrival (office, hardware, network access).

8. Ensure mutual understanding of the work contract and matters of protocol.

9. Facilitate bonding both on arrival (through informal but structured events/opportunities) and pre-arrival (via online social networking).

10. Include established teachers in the program, especially as mentors.

11. Vary group dynamics (senior/junior, peer/peer, individual/small group/whole cohort etc.).

12. Keep the orientation free of unrelated matters/events.

The efficacy of several of these principles is supported in Van den Branden's (2006) overview of studies on language teacher training. Key points of similarity are: the organization of the training program itself is crucial to its success; teachers want the practical realities of their classroom situation to dictate how theory is applied; teachers need to be supplied with readymade materials (e.g. syllabuses) in order to activate unfamiliar approaches; and senior teachers can have a significant psychological and pedagogical impact as role models.

This paper has reaffirmed the value of program evaluation, not as 'something done to us by external experts for mandated purposes' (Norris, 2009, p.7), but rather as an internally motivated, responsive, and necessary practice to inform program improvement. The length of 
the above lists indicates how much we learned. Viewed positively, we did not expect to garner so many new ideas for implementation. Viewed critically, we underestimated the extent of the challenges in our previous practice. We feel that this evaluation has contributed to knowledge of one area of language program management that has been previously neglected - not only by us but also, we suspect (given the dearth of published studies), by EFL managers in general.

\section{Acknowledgements}

We would like to thank Alice Lee, Jo Mynard, Christopher Stillwell and two anonymous reviewers for their feedback on earlier drafts of this paper. We are also grateful to Nicola Galloway and the Kanda University lecturers who participated in the evaluation.

\section{References}

Abbott, L., Moran, A., \& Clarke, L. (2009). Northern Ireland beginning teachers' experiences of induction: The 'haves' and the 'have nots'. European Journal of Teacher Education, $32,95-110$.

Barlow, J., \& Antoniou, M. (2007). Room for improvement: The experiences of new lecturers in higher education. Innovations in Education and Teaching International, 44, 67-77.

Campbell, J., \& Li, M. (2008). Asian student's voices: An empirical study of Asian students' learning experiences at a New Zealand university. Journal of Studies in International Education, 12, 375-396.

Carver, C.L., \& Feiman-Nemser, S. (2009). Using policy to improve teacher induction: 
Critical elements and missing pieces. Educational Policy, 23, 295-328.

Davis, J., Sinicrope, C, \& Watanabe, Y. (2009). College foreign language program evaluation: current practice, future directions. In J. Norris, J. Davis, C. Sinicrope, \& Y. Watanabe (Eds.), Toward useful program evaluation in college foreign language education (pp. 209-226). Honolulu: University of Hawaii, National Foreign Language Resource Center.

Dunn, L., \& Wallace, M. (2006). Australian academics and transnational teaching: An exploratory study of their preparedness and experiences. Higher Education Research \& Development, 25, 357-369.

El-Shamy, S. (2003). Dynamic induction: Games, activities and ideas to revitalize your employee induction process. Aldershot: Gower.

Fresko, B., \& Nasser-Abu Alhija, F. (2009). When intentions and reality clash: Inherent implementation difficulties of an induction program for new teachers. Teaching and Teacher Education 25, 278-284.

Howe, E.R. (2006). Exemplary teacher induction: An international review. Educational Philosophy and Theory, 38, 287-297.

Jiang, X., Di Napoli, R., Borg, M., Maunder, R., Fry, H., \& Walsh, E. (2010). Becoming and being an academic: The perspectives of Chinese staff in two research-intensive UK universities. Studies in Higher Education, 35, 155-170.

Kelley, L.M. (2004). Why induction matters. Journal of Teacher Education, 55, 438-448.

Kiely, R. (2009). Small answers to the big question: Learning from language program evaluation. Language Teaching Research, 13, 99-116.

Kiely, R., \& Rea-Dickens, P. (2005). Program evaluation in language education. New York: Palgrave MacMillan. 
Lewis, M. (2005). Moving tales: Acculturation experiences of migrant women staff entering a New Zealand polytechnic. Higher Education Research \& Development, 24, 95-108.

Littrell, L., Salas, E., Hess, K., Paley, M., \& Riedel, S. (2006). Expatriate preparation: A critical analysis of 25 years of cross-cultural training research. Human Resource Development Review, 5, 355-388.

Major, E. (2005). Co-national support, cultural therapy, and the adjustment of Asian students to an English-speaking university culture. International Education Journal, 6, 84-95.

Norris, J.M. (2009). Understanding and improving language education through program evaluation: Introduction to the special issue. Language Teaching Research, 13, 7-13.

Norris, J., Davis, J., Sinicrope, C. \& Watanabe, Y. (Eds). (2009). Toward useful program evaluation in college foreign language education. Honolulu: University of Hawaii, National Foreign Language Resource Center.

Patton, M.Q. (2008). Utlization-focused evaluation ( $4^{\text {th }}$ ed.). Thousand Oaks, CA: Sage.

Rea-Dickins, P., \& Germaine, K. P. (Eds.). (1998). Managing evaluation and innovation in language teaching. Harlow: Longman.

Sawir, E., Marginson, S., Deumert, A., Nyland, C., \& Ramia, G. (2008). Loneliness and international students: An Australian study. Journal of Studies in International Education, 12, 148-180.

Stanulis, R.N., \& Floden, R.E. (2009). Intensive mentoring as a way to help beginning teachers develop balanced instruction. Journal of Teacher Education, 60, 112-122.

Stirzaker, R. (2004). Staff induction: Issues surrounding induction into international schools. Journal of Research in International Education, 3, 31-49.

Trowler, P., \& Knight. P. (2000). Coming to know in higher education: Theorising faculty entry to new work contexts. Higher Education Research \& Development, 19, 27-42.

Trowler, P., \& Knight. P. (1999). Organizational socialization and induction in universities: 
Reconceptualizing theory and practice. Higher Education, 37, 177-195.

Van den Branden, K. (2006). Task-based language teaching: From theory to practice. Cambridge: Cambridge University Press.

White, R., Hockey, A., van der Horst, J., \& Laughner, M. (2008). From teacher to manager: Managing language teaching organizations. Cambridge: Cambridge University Press.

Watanabe, Y., Norris, N., \& Gonzalez-Moret, M. (2009). Identifying and responding to evaluation needs in college foreign language programs. In J. Norris, J. Davis, C. Sinicrope, \& Y. Watanabe (Eds.), Toward useful program evaluation in college foreign language education (pp. 5-56). Honolulu: University of Hawaii, National Foreign Language Resource Center.

Wong, H., Britton, T., \& Ganser, T. (2007). What the world can teach us about new teacher induction. In A. Ornstein, E. Pajaki, \& S. Ornstein (Eds.), Contemporary issues in curriculum (pp. 327-333). Boston, MA: Pearson.

Wood, E., \& El Mansour, B. (2010). Integrative literature review: Performance interventions that assist Chinese expatriates' adjustment and performance: Toward a conceptual approach. Human Resource Development Review, 9, 194-218.

Yang, W. (2009). Evaluation of teacher induction practices in a US university English language program: Towards useful evaluation. Language Teaching Research, 13, 77-98 


\begin{tabular}{|c|c|c|c|c|}
\hline Perspective & $N$ & Time frame & Purpose & Method \\
\hline $\begin{array}{l}\text { ELI } \\
\text { management }\end{array}$ & 4 & $\begin{array}{l}\text { Prior to } \\
\text { semester } 1\end{array}$ & $\begin{array}{l}\text { to specify the intended outcomes of, and } \\
\text { degree of satisfaction with, current } \\
\text { orientation practices }\end{array}$ & $\begin{array}{l}\text { Self-report; } \\
\text { Interview }\end{array}$ \\
\hline $\begin{array}{l}\text { New ELI } \\
\text { lecturers }\end{array}$ & 21 & Day 1 of orientation & $\begin{array}{l}\text { to investigate perceptions and needs } \\
\text { before orientation commences }\end{array}$ & Survey \\
\hline $\begin{array}{l}\text { New ELI } \\
\text { lecturers }\end{array}$ & 16 & $\begin{array}{l}4 \text { days after } \\
\text { completion of } \\
\text { orientation }\end{array}$ & $\begin{array}{l}\text { to capture immediate reactions to the } \\
\text { orientation upon completion }\end{array}$ & Survey \\
\hline $\begin{array}{l}\text { New ELI } \\
\text { lecturers }\end{array}$ & 10 & End of semester 1 & $\begin{array}{l}\text { to investigate views on the orientation } \\
\text { after one semester's experience }\end{array}$ & $\begin{array}{l}\text { Focus } \\
\text { groups; } \\
\text { Survey }\end{array}$ \\
\hline $\begin{array}{l}\text { Experienced } \\
\text { ELI lecturers }\end{array}$ & 14 & End of semester 1 & $\begin{array}{l}\text { to investigate views on the orientation } \\
\text { after more than one year's experience }\end{array}$ & $\begin{array}{l}\text { Focus } \\
\text { groups; } \\
\text { Survey }\end{array}$ \\
\hline
\end{tabular}

Table 1 Overview of data collection procedures 
$\%$ of Text Coverage

Key Areas

Components

$\begin{array}{cc}\text { intended } & \begin{array}{c}\text { satisfaction } \\ \text { with current }\end{array} \\ \text { outcome } & \text { practice }\end{array}$

Contract formal signing, specific details, renewal requirements

$9.13 \%$

$10.41 \%$

Background to the history, structure, campus, key personnel

Institution

$5.19 \% \quad 1.30 \%$

Professional institutional procedures, grievance procedure,

Protocol dress code, relationships with students

$2.40 \% \quad 0.54 \%$

Financial employer loan for set-up costs

Assistance

$1.92 \% \quad 2.70 \%$

Work Space

office, computer, email/log-in, miscellaneous

$1.85 \%$

$13.61 \%$

Table 2 Administrative domain 
$\%$ of Text Coverage

Key Areas

Components

$\begin{array}{ll}\text { Cultural } & \text { relevant concepts }- \text { e.g. status } \\ \text { Knowledge } & \text { of 'lecturer' in Japanese society }\end{array}$

Everyday bank account, insurance, alien

Bureaucracy

Place to Live registration card

apartment hunting, furnishings, utilities satisfaction with

current practice intended outcome

$3.27 \%$

$1.43 \%$

Table 3 Civilian domain 
$\%$ of Text Coverage

Key Areas

Components

intended outcome satisfaction with

current practice

Courses

course

content,

materials,

resources/technology/facilities, fellow

$16.17 \%$

$13.04 \%$

teachers, first lessons

Research

duties, existing institutional projects

$5.22 \%$

Students

level of English proficiency, motivation,

typical behaviour

$4.33 \%$

$3.32 \%$

Philosophy

design of curriculum and learning environments

$3.93 \%$

Professional

awareness of opportunities

Development
$3.71 \%$

Table 4 Academic Domain 
$\%$ of Text Coverage

Key Areas

Components

satisfaction with

intended outcome current practice

Emotional ensure newcomers feel secure and supported

Stability

Bonding facilitate positive collegial relationships

$3.27 \%$

Formal introduce newcomers to university

Recognition community

$1.43 \%$

$8.27 \%$

Table 5 Interpersonal domain 


\begin{tabular}{|c|c|c|c|c|}
\hline & high & moderate & low & $\begin{array}{c}\text { non- } \\
\text { existent }\end{array}$ \\
\hline \multicolumn{5}{|l|}{ History } \\
\hline history of the university & $4.8 \%(1)$ & $38.1 \%(8)$ & $57.1 \%(12)$ & $0 \%(0)$ \\
\hline history of the ELI & $0 \%(0)$ & $47.6 \%(10)$ & $42.9 \%(9)$ & $4.8 \%(1)$ \\
\hline \multicolumn{5}{|l|}{ Job details } \\
\hline educational philosophy of the ELI & $9.5 \%(2)$ & $76.2 \%(16)$ & $14.3 \%(3)$ & $0 \%(0)$ \\
\hline your contractual obligations & $52.4 \%(11)$ & $38.1 \%(8)$ & $9.5 \%(2)$ & $0 \%(0)$ \\
\hline current ELI colleagues & $4.8 \%(1)$ & $33.3 \%(7)$ & $42.9 \%(9)$ & $19 \%(4)$ \\
\hline what you will be teaching/advising & $0 \%(0)$ & $47.6 \%(10)$ & $38.1 \%(8)$ & $14.3 \%(3)$ \\
\hline your role as an ELI researcher & $4.8 \%(1)$ & $33.3 \%(7)$ & $57.1 \%(12)$ & $4.8 \%(1)$ \\
\hline professional development opportunities & $4.8 \%(1)$ & $47.6 \%(10)$ & $42.9 \%(9)$ & $4.8 \%(1)$ \\
\hline \multicolumn{5}{|l|}{ Technology } \\
\hline computer assisted language learning & $9.5 \%(2)$ & $47.6 \%(10)$ & $38.1 \%(8)$ & $4.8 \%(1)$ \\
\hline online course management systems & $0 \%(0)$ & $66.7 \%(14)$ & $28.6 \%(6)$ & $4.8 \%(1)$ \\
\hline \multicolumn{5}{|l|}{ Life in Japan } \\
\hline Japanese culture & $71.4 \%(15)$ & $19 \%(4)$ & $9.5 \%(2)$ & $0 \%(0)$ \\
\hline Japanese education system & $61.9 \%(13)$ & $28.6 \%(6)$ & $9.5 \%(2)$ & $0 \%(0)$ \\
\hline Japanese university students & $28.6 \%(6)$ & $47.6 \%(10)$ & $23.8 \%(5)$ & $0 \%(0)$ \\
\hline practical life matters in Japan & $61.9 \%(13)$ & $23.8 \%(5)$ & $14.3 \%(3)$ & $0 \%(0)$ \\
\hline housing in Japan & $33.3 \%(7)$ & $38.1 \%(8)$ & $28.6 \%(6)$ & $0 \%(0)$ \\
\hline
\end{tabular}

Table 6 Recruits' levels of knowledge 


\begin{tabular}{|c|c|c|c|c|c|}
\hline & a lot & $\begin{array}{c}\text { a reasonable } \\
\text { amount }\end{array}$ & a little & nothing & N/A \\
\hline job interview & $23.8 \%(5)$ & $71.4 \%(15)$ & $4.8 \%(1)$ & $0.0 \%(0)$ & $0.0 \%(0)$ \\
\hline $\begin{array}{l}\text { people who have worked } \\
\text { the ELI }\end{array}$ & $25.0 \%(5)$ & $20.0 \%(4)$ & $35.0 \%(7)$ & $15.0 \%(3)$ & $5.0 \%(1)$ \\
\hline $\begin{array}{l}\text { communications from } \\
\text { senior ELI academic staff }\end{array}$ & $9.5 \%(2)$ & $52.4 \%(11)$ & $14.3 \%(3)$ & $9.5 \%(2)$ & $14.3 \%(3)$ \\
\hline $\begin{array}{l}\text { website for incoming ELI } \\
\text { staff }\end{array}$ & $14.3 \%(3)$ & $61.9 \%(13)$ & $23.8 \%(5)$ & $0.0 \%(0)$ & $0.0 \%(0)$ \\
\hline ELI and university website & $19.0 \%(4)$ & $42.9 \%(9)$ & $33.3 \%(7)$ & $0.0 \%(0)$ & $4.8 \%(1)$ \\
\hline
\end{tabular}

Table 7 Sources of recruits' knowledge 


\begin{tabular}{|c|c|c|c|}
\hline Domain & $\begin{array}{l}\% \text { of Text } \\
\text { Coverage }\end{array}$ & Sub-Topics & $\%$ of Text Coverage \\
\hline \multirow[t]{3}{*}{ Academic } & $42.15 \%$ & Courses & $39.02 \%$ \\
\hline & & Self-access Learning & $5.39 \%$ \\
\hline & & Research & $3.08 \%$ \\
\hline \multirow[t]{2}{*}{ Civilian } & $15.89 \%$ & Place to Live & $13.24 \%$ \\
\hline & & Cultural Knowledge & $2.65 \%$ \\
\hline \multirow[t]{4}{*}{ Administrative } & $12.07 \%$ & Work Space & $4.36 \%$ \\
\hline & & Background to Institution & $3.56 \%$ \\
\hline & & Contract & $2.95 \%$ \\
\hline & & Professional Protocol & $1.20 \%$ \\
\hline \multirow[t]{2}{*}{ Interpersonal } & $4.96 \%$ & Bonding & $4.43 \%$ \\
\hline & & Emotional Stability & $0.53 \%$ \\
\hline \multirow[t]{2}{*}{ Other } & $24.28 \%$ & Overall Comments & $19.28 \%$ \\
\hline & & $\begin{array}{l}\text { Administering Proficiency } \\
\text { Test }\end{array}$ & $7.91 \%$ \\
\hline
\end{tabular}

Table 8 Topics raised by first year lecturers at the end of one semester 


\begin{tabular}{|c|c|c|c|}
\hline Domain & $\begin{array}{l}\% \text { of Text } \\
\text { Coverage }\end{array}$ & Sub-Topics & $\%$ of Text Coverage \\
\hline \multirow[t]{5}{*}{ Academic } & $57.55 \%$ & Courses & $30.24 \%$ \\
\hline & & Self-access Learning & $14.09 \%$ \\
\hline & & Students & $12.57 \%$ \\
\hline & & Philosophy & $3.58 \%$ \\
\hline & & Research & $2.90 \%$ \\
\hline \multirow[t]{2}{*}{ Civilian } & $10.16 \%$ & Place to Live & $5.12 \%$ \\
\hline & & Cultural Knowledge & $5.05 \%$ \\
\hline \multirow[t]{3}{*}{ Administrative } & $14.06 \%$ & Contract & $8.89 \%$ \\
\hline & & Work Space & $3.51 \%$ \\
\hline & & Background to Institution & $2.95 \%$ \\
\hline \multirow[t]{2}{*}{ Interpersonal } & $3.42 \%$ & Bonding & $2.39 \%$ \\
\hline & & Emotional Stability & $0.53 \%$ \\
\hline \multirow[t]{2}{*}{ Other } & $28.07 \%$ & Overall Comments & $13.21 \%$ \\
\hline & & $\begin{array}{l}\text { Administering Proficiency } \\
\text { Test }\end{array}$ & $14.86 \%$ \\
\hline
\end{tabular}

Table 9 Topics raised by experienced lecturers during stimulated recall activity 